\title{
FOCAL AND MULTIFOCAL DIABETIC NEUROPATHIES
}

\author{
Gérard Said
}

\begin{abstract}
Diabetic neuropathy is the most common neuropathy in industrialized countries, with a remarkable range of clinical manifestations. The vast majority of the patients with clinical diabetic neuropathy have a distal symmetrical form that progress following a fiber-length dependent pattern, with predominant sensory and autonomic manifestations. This pattern of neuropathy is associated with a progressive distal axonopathy. Patients are exposed to trophic changes in the feet, pains and autonomic disturbances. Less often, diabetic patients may develop focal and multifocal neuropathy that includes cranial nerve involvement, limb and truncal neuropathies. This neuropathic pattern tends to occur after 50 years of age, mostly in patients with longstanding diabetes mellitus. The LDDP does not show any trend to improvement and either relentlessly progresses or remain relatively stable over years. Conversely the focal diabetic neuropathies, which are often associated with inflammatory vasculopathy on nerve biopsies, remain self limited, sometimes after a relapsing course.
\end{abstract}

KEY WORDS: diabetic neuropathy, diabetic ophthalmoplegia, proximal diabetic neuropathy, neuropathology, nerve biopsy.

\begin{abstract}
Neuropatia diabética focal e multifocal
RESUMO - A neuropatia diabética é a mais predominante das neuropatias nos países industrializados apresentando uma gama variável de manifestações clinicas. A maioria dos pacientes com neuropatia diabética apresenta uma forma simétrica distal que progride para um padrão fibra comprimento dependente com manifestações sensitivas e autonomicas. Este tipo de neuropatia é associado com uma axonopatia distal progressiva. Os pacientes apresentam modificações tróficas nos pés, dores e distúrbios autonômicos. Menos freqüentemente os pacientes diabéticos podem desenvolver neuropatia focal e multifocal que incluem envolvimento de nervos cranianos, tronco e membros inferiores. Este padrão de neuropatia é mais freqüente em pacientes com mais de 50 anos e com longa historia de diabetes. Este tipo de neuropatia fibra-comprimento dependente não apresenta melhora, progride lentamente ou permanece estável por vários anos. As neuropatias focais que são associadas freqüentemente com vasculopatias inflamatórias nas biópsias de nervo, permanecem auto limitadas por vezes com surtos de remissão.
\end{abstract}

PALAVRAS-CHAVE: neuropatia diabética, oftalmoplegia diabética, neuropatia proximal diabética, neuropatologia, biopsia de nervo.

Diabetes mellitus is the most common cause of neuropathy in the world and an increasing burden in countries where obesity prevalence progresses. Most clinical manifestations of diabetic neuropathy had been identified during the second half of the nineteenth century, but our knowledge on the pathology of diabetic neuropathies has been increased by the unexpected finding of inflammatory lesions in focal diabetic neuropathies.

Given that diabetes affects approximately 246 million people worldwide, it is estimated that 20-30 million people worldwide are affected by symptomatic diabetic neuropathy. Growing rates of obesity and the associated increase in the prevalence of type 2 diabetes could cause these figures to double by the year $2030^{\prime}$. The prevalence of diabetic neuropathy also in- creases with time and poor glycemic control ${ }^{2}$, and severe diabetic polyneuropathy can develop in young adults within a few months after the onset of type 1 diabetes if the diabetes is poorly controlled ${ }^{3}$.

However, epidemiology of focal and multifocal diabetic neuropathy is not strictly correlated with duration and intensity of diabetes, mainly because type-2 diabetes is silent, on average for more than 10 years, until the occurrence of symptomatic complications. More than eighty percent of the patients with clinical diabetic neuropathy have a distal symmetrical form that progress following a fibre-length dependent pattern, with predominant sensory and autonomic manifestations ${ }^{4,5}$. In the others, focal neuropathies occur, both in men and women over 50 years of age, most with long standing type-1 or type-2 di-

Médecin Consultant de l'Hôpital de Bicêtre; Université Paris-Sud

Received 26 September 2007. Acepted 22 October 2007.

Prof. Gérard Said - Université Paris-Sud - 94275 Le Kremlin Bicêtre, France. E-mail: gerard.said@bct.aphp.fr 
abetes. They often reveal type-2 diabetes and pose specific diagnostic and therapeutic problems, which are different from those encountered in distal symmetrical, length-dependent diabetic polyneuropathy, with which they are often associated. Besides the clinical pattern of the neurological deficit, a major difference exists between the common length-dependent diabetic polyneuropathy (LDDP) and focal or multifocal neuropathies that occur in diabetic patients. The LDDP does not show any trend to improvement and either relentlessly progresses or remain relatively stable over years. Conversely the focal diabetic neuropathies may relapse but their course remains self limited. However, multifocal neuropathy can lead to very disabling neurological deficit. In this paper we will review the clinical and pathological aspects of diabetic neuropathies, which are often associated with inflammatory phenomena.

Focal and multifocal diabetic neuropathies encompass cranial neuropathy, truncal neuropathy and limb neuropathy. Oculomotor nerve palsies are the most common if not the only cranial neuropathy observed in diabetic patients.

\section{CRANIAL NEUROPATHY}

Historical background - In 1905, Dieulafoy published a series of 58 personal cases in which he described most of the clinical characteristics of diabetic ophthalmoplegia ${ }^{6}$ and, in 1935, Waite and Beetham performed the first epidemiological study on the subject in which they compared the occurrence of oculomotor palsy in 2002 diabetic patients with 457 non diabetic patients 7 . A series of other clinical reports have refined our knowledge on the subject but pathological studies remain scanty with only a few autopsy cases studied and the pathophysiology of oculomotor palsies in diabetic patients a matter of discussion.

Like focal neuropathy observed in other sites of the body, diabetic ophthalmoplegia is an uncommon event. The estimated incidence ranges from 0.8 to 1.8 percent ${ }^{7,8}$. It is interesting to note the frequency of oculomotor palsy was 0.8 percent in patients of less than 45 years of age, versus 2.1 percent after 45 years $^{8}$.

Frequency of involvement of the different oculomotor nerves - The third and sixth cranial nerves are the most commonly affected. In a series of 58 cases of diabetic ophthalmoplegia, Dieulafoy reported 35 cases of sixth nerve palsy, 12 cases of third nerve palsy, 5 cases of fourth nerve palsy, and 6 cases of external ophthalmoplegia ${ }^{6}$. In an analysis of 811 cases of oculomotor palsies, diabetes accounted for 2.6 percent of third nerve palsy, 1.9 percent of sixth nerve palsy and
0.6 percent of fourth nerve palsy ${ }^{9}$. Finally, in Zorrilla and Kozak's series of 24 cases, 17 patients had an involvement of the third nerve, including two bilaterally, and 7 cases of sixth nerve palsy, but no fourth nerve involvement ${ }^{10}$.

Clinical manifestations - In virtually all cases diabetic ophthalmoplegia occurs in diabetic patients over 50 years of age, both in type- 1 and type-2 diabetic patients. The onset is rapid, within a day or two. In many cases the patient experiences pains during a few hours to a few days before noticing diplopia. Pain thus preceded the onset of diplopia in 14 out of the 25 patients reported by Green et al..". Pain seems more common when the third cranial nerve is affected than when the sixth nerve is involved. Pain is usually aching, behind or above the eye, and sometimes more diffuse but always homolateral to the oculomotor palsy. Pain is often attributed to the involvement of the first and second divisions of the trigeminal nerve within the cavernous sinus, or to activation of pain-sensitive endings within the sheath of the third nerve as it traverses the cavernous sinus. Pains do not persist after the onset of diplopia.

Oculomotor dysfunction is often incomplete when the third nerve is involved one or two muscles only may be paralyzed. In their series of 22 episodes of ophthalmoplegia observed in 20 patients, Goldstein and Cogan mentioned 12 episodes of complete dysfunction, 3 episodes of nearly complete dysfunction and 3 of partial paralysis ${ }^{12}$. Ptosis is marked, the eye is deviated outward when the internal rectus muscle is affected; the patient is unable to move the eye medially, upward or downward. Pupillary innervation is often spared. Sparing of pupillary function permits to differentiate third nerve palsy of diabetic origin from third nerve palsy resulting from compression of the nerve by an aneurysm of the posterior communicating artery, in which pupillary dilatation is very common. Nowadays however a brain and angio-MRI are mandatory tp to exclude another cause of ophthalmoplegia. Centrofascicular lesion found by Asbury and coworkers at autopsy of a patient with third nerve palsy accounts for sparing of pupillary function ${ }^{13}$ due to the relative intactness of pupillomotor fibers which are peripherally placed in the third nerve. Spontaneous and complete recovery invariably occurs within an average 2-3 months, independently of the quality of control of hyperglycemia.

Pathology - Two serial sections studies performed in patients with third cranial nerve palsy demonstrated a centrofascicular lesion of the nerve in its intra- 
cavernous portion ${ }^{14}$. The fibers placed at the periphery of the nerve trunk were relatively spared, which accounted for the pupillary sparing. In both reports the authors suggested that the observed centrofascicular lesions of the third nerve were most likely ischemic in origin ${ }^{13}$.

\section{TRUNCAL NEUROPATHIES}

Truncal neuropathy is unilateral or predominantly so. The onset is abrupt or rapid, with pains or dysesthesias as the main features. The pain may have a spinal root distribution and is almost made worse by contact and at night ${ }^{15,16}$. Weakness of abdominal muscles occurs. Isolated involvement of peripheral nerve of the limbs is extremely rare, with the exception of nerve entrapment.

\section{PROXIMAL DIABETIC NEUROPATHY (PDN) OF THE LOWER LIMBS}

Clinical and epidemiological aspects - Diabetic patients, usually over the age of 50, may present proximal neuropathy of the lower limbs characterized by a variable degree of pain and sensory loss associated with proximal muscle weakness and atrophy. This syndrome, which was originally described by Bruns in $1890^{17}$, has been subsequently reported under the terms of diabetic myelopathy ${ }^{18}$, diabetic amyotrophy ${ }^{19}$, femoral neuropathy ${ }^{20,21}$, proximal diabetic neuropathy ${ }^{22,23}$, femoral-sciatic neuropathy ${ }^{24}$ and the Bruns-Garland syndrome ${ }^{25,26}$. The neurological picture is limited to the lower limbs and is usually asymmetrical ${ }^{27}$. The neurological picture is usually unilateral. Clinically, the different patterns and the course of PDN strikingly differ from those of length dependent diabetic polyneuropathy. In our study on PDN that included 27 patients, 24 with type-2 diabetes, 3 with type-1 diabetes; the mean age at diagnosis was 62 years (range 46-71); the male:female ratio was $16: 11^{28}$.

Clinical features of PDN: The onset of the neuropathy is acute or subacute. The patients complain of numbness or pains of the anterior aspect of the thigh, often of the burning type, worse at night and by contact. Difficulty in walking and climbing stairs is common, due to weakness of the quadriceps and iliopsoas muscles. Early muscle wasting is often easier to palpate than to see in fatter patients. The patellar reflex is decreased or more often abolished. The syndrome progresses over weeks or months in most cases, then stabilises and spontaneous pains decreases, sometimes rapidly. In approximately one third of the patients there is a definite sensory loss over the anterior aspect of the thigh, and in the others a painful contact dysesthesiae in the distribution of the cutane- ous branches of the femoral nerve, without definite sensory loss. Another cause, mechanical or malignant for example, must always be excluded before concluding that the neuropathy is related to diabetes.

In most cases the patient's condition improves after months, but sequelae including disabling weakness and amyotrophy, sensory loss and patellar areflexia are common. In a survey of long-term followup of up to 14 years recovery began after a median interval of 3 months (range 1-12 months). Pain was the first symptom to improve, resolution beginning within a few weeks and being almost complete by 12 months. Residual discomfort in the patients of may take up to 3 years to subside ${ }^{29}$. Relapses on the other side are common, sometimes in spite of good diabetic control. In one fifth of our patients relapses occurred on the other side within a few months. Thus the clinical features of PDN with frequent motor involvement, asymmetry of the deficit, gradual yet often incomplete spontaneous recovery, markedly differs from those of LDDP in which the sensory deficit is associated with motor signs only in extreme cases, and which virtually never improves spontaneously.

Pathological aspects of PDN - In a recent morphological study of biopsy specimens of the intermediate cutaneous nerve of the thigh, a sensory branch of the femoral nerve which conveys sensations from the anterior aspect of the thigh, a territory commonly involved in PDN we found that the pathology of proximal nerves varied with the clinical aspects of the neuropathy.

In the patients with the most severe sensory and motor deficit examination of the biopsy specimen revealed lesions characteristic of severe nerve ischemia, including total axon loss in the two patients with the most severe deficit, and centrofascicular degeneration of fibers in one, following a pattern observed in nerve ischemia. Lesions of nerve fibers coexisted with occlusion of perineurial blood vessels as reported in the only detailed post-mortem study of PDN available, in which the authors found a small infiltration with mononuclear cells associated with the occlusion of an interfascicular artery of the obturator nerve in a diabetic patient with proximal and distal deficit of the left lower limb.

In a patient of our series ${ }^{28}$, who developed a rapid, asymmetrical, distal, sensori-motor deficit shortly after the onset of the proximal deficit, recent occlusion of a perineurial blood vessel and perivascular, perineurial and subperineurial inflammatory infiltration with mononuclear cells were demonstrated, along with axonal degeneration of the majority of 
nerve fibers of the superficial peroneal nerve. Mixed, axonal and demyelinative nerve lesions were associated with increased endoneurial cellularity made of mononuclear cells that suggested the presence of a low grade endoneurial inflammatory process in four of them. In a recent study of patients with extremely painful PDN, we found similar inflammatory lesions with B and T lymphocytes mixed with macrophages. Similar observations were confirmed by others ${ }^{30,31}$

\section{MULTIFOCAL DIABETIC NEUROPATHY (MDN)}

Clinical aspects - Multifocal neuropathy is characterized by successive or simultaneous involvement, over weeks or months, of roots and nerves of the lower limbs, the trunk and the upper extremities. In a recent study of 22 diabetic patients with MDN, for which other causes of neuropathy were excluded by appropriate investigations, including biopsy of a recently affected sensory nerve, three patients had a relapsing, the others an unremitting subacute-progressive course ${ }^{32}$. Painful multifocal sensory-motor deficit progressed over 2 to 12 months. Distal lower limbs were involved in all patients, unilaterally in seven, bilaterally in the others, with an asynchronous onset in most cases. In addition, proximal deficit of the lower limbs was present on one side in seven pa-

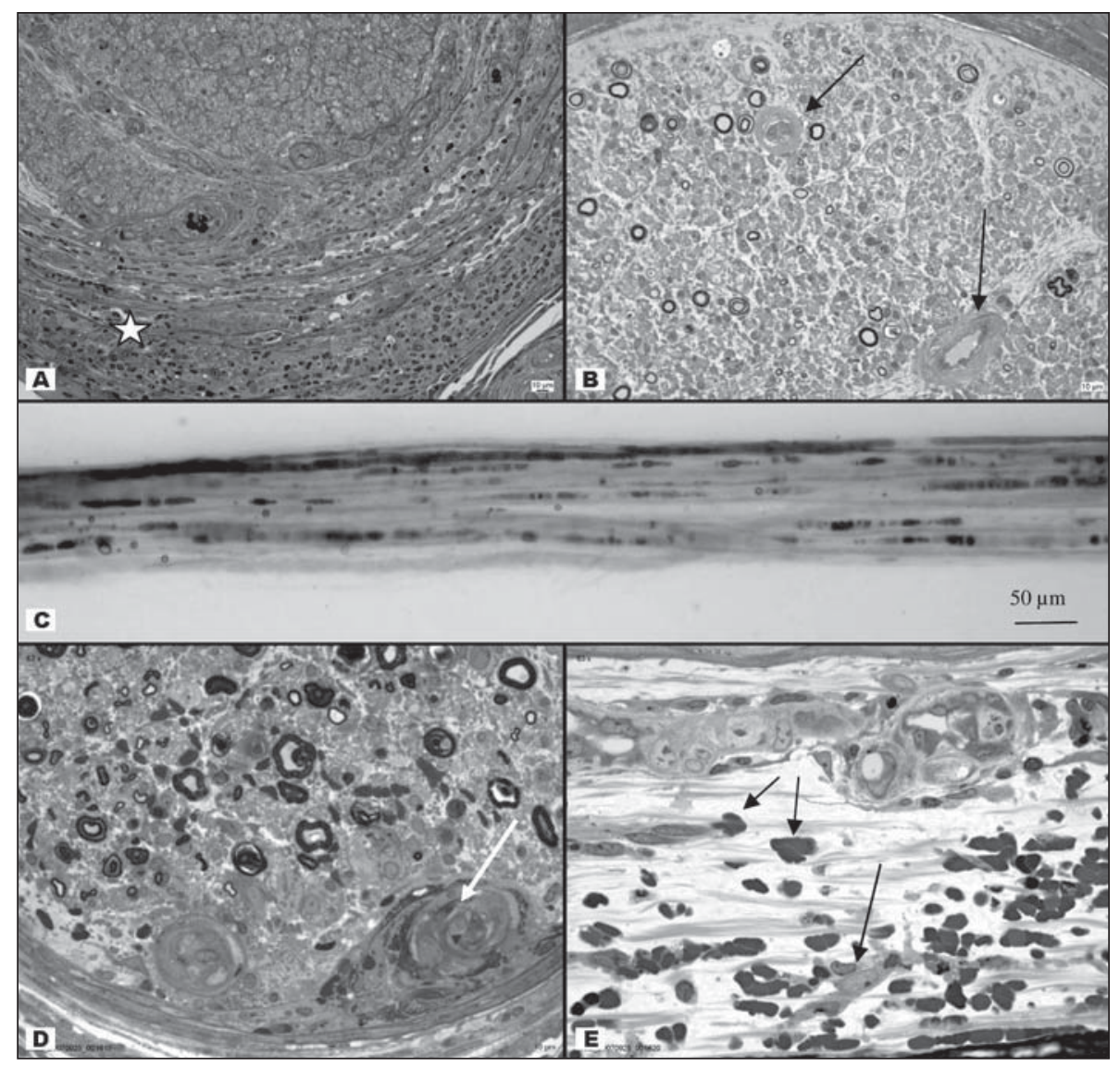

Figure. (A) Nerve biopsy of a patient with multifocal diabetic neuropathy showing massing inflammatory infiltration of mononuclear cells, almost exclusively lymphocytes with occasional plasma cells, in the epineurium and perineurium (star). Note the complete disappearance of nerve fibers from this fascicle. (B) Near complete loss of nerve fiber in this fascicle, associated with diabetic microangiopathy (arrows). (C) Group of osmicated teased fibers showing axonal degeneration of nearly all of them. (D) Cross section of a nerve biopsy specimen of a patient with multifocal diabetic neuropathy to show occlusion of a perineurial blood vessel (arrow) and endoneurial seepage of red cells, which are better seen on the longitudinal section of the same biopsy specimen. (E) Longitudinal section of the nerve biopsy specimen from the same patient as shown at the bottom left. Note the endoneurial blood vessel at the top of the picture and red cells in the endoneurium, some of which are already engulfed by macrophages (arrows). The plastic sections show at the top and at the bottom are one-micron thick and stained with thionine blue. 
tients, on both sides in six. Thoracic radiculo-neuropathy was present bilaterally in two patients, unilaterally in one ${ }^{32}$. The ulnar nerve was involved in one patient, the radial nerve in two. The cerebrospinal fluid protein ranged from 0.40 to $3.55 \mathrm{~g} / \mathrm{L}$; mean: 0.87 g/L. EMG showed an axonal pattern in all cases. MDN is comparable to the lumbosacral radiculoplexus neuropathy ${ }^{30}$, which can actually involve territories beyond the lumbosacral area. It is also obvious that multifocal neuropathy or lumbosacral radiculoplexopathy is not specific to diabetic patients, which underlines the need to exclude other causes of neuropathy in this setting, including a superimposed cause in diabetic patients, such as necrotizing arteritis or chronic inflammatory demyelinating polyneuropathy, which may require specific treatment.

Pathological aspects of multifocal diabetic neuropathy (Figure) - Asymmetrical axonal lesions were present in all nerve specimens of patients with MDN. The mean density of myelinated and of umyelinated axons was reduced. On teased fibre preparations one third of the fibres were at different stages of axonal degeneration while $7 \%$ showed segmental demyelination or remyelination. Necrotizing vasculitis of perineurial and endoneurial blood vessels were found in six patients. Evidence of present or past endoneurial bleeding that included seepage of red cells, haemorrhage and/or ferric iron deposits were found in the majority of the specimens. Perivascular mononuclear cell infiltrates were present in the nerve specimens of 21/22 patients, prominently in 4 patients. In comparison, nerve biopsy specimens of 30 patients with severe LDDP showed mild epineurial mononuclear cell infiltrate in one patient and endoneurial seepage of red cells in one ${ }^{32}$.

Besides the high frequency both of endoneurial bleeding and of inflammatory infiltrates, occlusion of small and middle sized epineurial and perineurial arteries differentiate MDN from distal symmetrical polyneuropathy (DSP). The intensity and distribution of the lesions seemed more severe in MDN than in PDN but both patterns can be included in multifocal diabetic neuropathies. The outcome is better in MDN than in DSP. Improvement occurs in all patients after a few months, but sequelae are common.

The relationship between the occurrence of inflammatory infiltrates, vasculitis and diabetes is not clear. Small inflammatory infiltrates have been occasionally encountered in sural nerve biopsy specimens of diabetic patients with neurological deficit ${ }^{33}$ and in autonomic nerve bundles and ganglia ${ }^{34}$. Lesions of nerve fibres and of blood vessels due to dia- betes may trigger an inflammatory reaction and reactive vasculitis in some patients; alternatively diabetes may make the nerves more susceptible to inflammatory or immune processes. In both cases, lesions of epi- or perineurial blood vessels can induce ischemic nerve lesions responsible for severe proximal sensory and motor deficits. The role of inflammation in atherosclerotic lesions has been the subject of a number of investigations that underlined the complexity of mechanisms involved. Endothelial alterations seem to be one of the most important triggering factors of inflammation in this setting, along with release of growth factors, cytokines and especially interleukin 12. These phenomena are associated with cellular reaction that includes platelet activation and recruitment of white blood cells in the vessel wall 35,36 . Alteration of vessel structures by diabetes may initiate the inflammatory process. In any case, subacute inflammation constitutes an important component of nerve and root pathology is a significant proportion of diabetic patients who manifest disabling neuropathy, making it possible to treat. Most important$l y$, the presence of inflammatory phenomena in the nerves in this setting makes these diabetic neuropathies treatable.

Differential diagnosis - The different patterns of disabling neuropathies observed in diabetic patients are summarized in the Table. In focal neuropathy occurring in diabetic patients, a superimposed cause must always be excluded. In patients with ophthalmoplegia, preservation of pupillary motricity in nearly complete third nerve palsy strongly suggests a diabetic origin, however even in such case, it is wiser to perform a non invasive investigation of the area. Magnetic resonnance angiogram, which will permit to rule out a compressive lesion of the third nerve by a large aneurysm of the carotid artery within the cavernous sinus, of the posterior communicating artery, or a fusiform aneurysm of the top of the basilar artery. Imaging will also permit to exclude tumors occurring at the base of the brain or in the basal skull, or a minor stroke of the brainstem. In patients with progressive involvement of several cranial nerves without imaging abnormalities, examination of the CSF may detect malignant cells characteristic of carcinomatous meningitis. In diabetic patients who develop a focal or multifocal neuropathy of the limbs other causes than diabetes should also be considered. The first step in this context is to determine if the lesions are located in the spinal roots or in the peripheral nerves. Distinction of which may be difficult clinically and electrophysiologically. In addition, the lesions may be mixed. 
Table 1. Main features in different patterns of disabling neuropathies in diabetic patients.

\begin{tabular}{llll}
\hline & $\begin{array}{l}\text { Length dependent } \\
\text { polyneuropathy }\end{array}$ & CIDP in diabetic patients & $\begin{array}{l}\text { Focal/Multifocal } \\
\text { diabetic neuropathy }\end{array}$ \\
\hline Pains & Frequent in distal limbs & Occasionnal & Present in most cases \\
Weakness & Minor, distal symmetrical & Common, often severe & Common - asymmetrical \\
proximal and distal & - nerve or root territory \\
Distal symmetrical sensory loss & $\begin{array}{l}\text { Length dependent } \\
\text { predominates on pain and }\end{array}$ & $\begin{array}{l}\text { Variable - predominates } \\
\text { on proprioception }\end{array}$ & Variable \\
temperature sensations & Common & \\
Sensory ataxia & Rare & Uncommon & Uncommon \\
CSF Protein & Common & increased & Uncommon \\
Electrophysiological test & Variable & Mixed axonal and & increased \\
Progression & symmetrical & demyelinative & Axonal pattern, multifocal \\
Nerve biopsy & Years & Weeks or months & Weeks or months \\
Response to high doses & Massive axonal loss & Variable axon loss and & Inflammation, vasculopathy \\
intraveinous immunoglobulins & No & demyelination & and axon loss \\
Response to corticosteroids & No & Variable & Variable
\end{tabular}

A nerve and a muscle biopsy may be considered, especially when another cause of focal or multifocal neuropathy is considered. When a diabetic patient develops proximal weakness without much pain, a superimposed cause of motor deficit including motor neuropathy and motor neuron disease must be considered, and appropriate investigations undertaken.

\section{TREATMENT OF FOCAL AND MULTIFOCAL DIABETIC NEUROPATHIES}

Proximal diabetic neuropathy is often very painful and often pains resist to conventional treatments. Treatment with corticosteroids can be considered in such cases, for a few weeks or months, with adjustment of diabetic control. There is no need to treat all patients with proximal diabetic neuropathy since spontaneous recovery occurs in spite of the presence of inflammatory lesions on nerve biopsy specimens ${ }^{37}$. When multifocal nerve lesions occur we think that treatment with corticosteroids is mandatory. We suggest starting with prednisone $0.75 \mathrm{mg} / \mathrm{kg}$ body weight/day for 3-4 weeks, then taper gently. Needless to say that diabetic control must be adjusted after introduction of corticosteroids. Ophthalmoplegia improves without treatment but relapses occur.

In summary, both metabolic and ischemic mechanisms may play a role in diabetic neuropathies, the metabolic factor seems to prevail in LDDP, while a superimposed inflammatory process and ischemic nerve lesions seem responsible for severe forms of focal neuropathies. The thickening and hyalinisation of the walls of small blood vessels, which corresponds to reduplication of the basal lamina around endothelial cells suggested a role for nerve ischemia in diabetic neuropathy. Identification of inflammatory phenomena in focal and multifocal neuropathy permitted new therapeutic approach in some of these disabling neuropathies.

\section{REFERENCES}

1. International Diabetes Federation [http://www.idf.org/]

2. Martin CL, et al. Neuropathy among the Diabetes Control and Complications Trial Cohort 8 years after trial completion Diabetes Care 2006;29: 340-344.

3. Said G, Bigo A, Améri A, Gayno J-P, Elgrably F, Chanson P, Slama G. Uncommon early onset neuropathy in diabetic patients. J Neurol 1998;245:61-68.

4. Palumbo PJ, Elveback LR, Whisnant JP. Neurologic complications of diabetic mellitus: transient ischemic attack, stroke and peripheral neuropathy. In Schoenberg BS (Ed). Advances in neurology. New York: Raven Press, 1978;19:593-601.

5. Freitas, Nascimento OJM, Chimelli L. Neuropatia diabética. I - conceito; epidemiologia, classificaçao, quadro clinico e electroneuromiografico: estudo de 210 casos. Rev Bras Neurol 1992;28:69-73.

6. Dieulafoy G. Clinique Médicale de l'Hotel-Dieu de Paris 1905-1906. Paris: Masson et Cie 1906:130-154

7. Waite JH, Beetham VP. The visual mechanisms in diabetes mellitus (a comparative study of 2002 diabetics and 457 non diabetics). N Engl J Med 1935;212:429-443.

8. Dollfus M. Examen ophtalmologique de 1300 diabétiques. XVII congrès international d'Ophtalmologie. Acta Concil 1954:119-127.

9. Rucker CW. Paralysis of the third, fourth and sixth cranial nerves. Am J Ophthal 1958;46:787-794.

10. Zorrilla E, Kozak GP. Ophthalmoplegia in diabetes mellitus. Ann Intern Med 1967:5:968-977.

11. Green WR, Hackett R, Schlezinger NS. Neuro-ophthalmologic evaluation of oculomotor nerve paralysis. Arch Ophthal 1964;72:154-167.

12. Goldstein JE, Cogan DG. Diabetic ophthalmoplegia with special reference to the pupil. Arch Ophthal 1960;64:592-600. 
13. Asbury AK, Aldredge H, Hershberg R, Fischer CM. Oculomotor palsy in diabetes mellitus: a clinico-pathological study. Brain 1970;93:555-566.

14. Dreyfus PM, Hakim S, Adams RD. Diabetic ophthalmoplegia. Arch Neurol Neurosurg Psychiatry 1957;77:337-349.

15. Ellenberg M. Diabetic truncal mononeuropathy: a new clinical syndrome. Diabetes Care 1978;1:10-13.

16. Stewart JD. Diabetic truncal neuropathy: topography of the sensory deficit. Ann Neurol 1989;25:233-238.

17. Bruns L. Ueber neuritische Lähmungen beim diabetes mellitus. Berl Klin Wochenscher 1890;27:509-515.

18. Garland HT, Taverner D. Diabetic myelopathy. Br Med J 1953;1:1505.

19. Garland HT. Diabetic amyotrophy. Br Med J 1955;2:1287-1290.

20. Goodman JI. Femoral neuropathy in relation to diabetes mellitus: report of 17 cases. Diabetes 1954;3:266-273.

21. Calverley JR, Mulder DW. Femoral neuropathy. Neurology 1960;10:963-967.

22. Asbury AK. Proximal diabetic neuropathy. Ann Neurol 1977;2:179.

23. Subramony SH, Wilbourn AJ. Diabetic proximal neuropathy. Clinical and electromyographic studies. J Neurol Sci 1982;53:293.

24. Skanse B, Gydell K. A rare type of femoral-sciatic neuropathy in diabetes mellitus. Acta Med Scand 1956;155:463-468.

25. Barohn RJ, Sahenk Z, Warmolts JR, Mendell JR. The Bruns-Garland syndrome (Diabetic amyotrophy) revisited 100 years later. Arch Neurol 1991;48:1130-1135.

26. Chokroverty S, Reyes MG, Rubino FA. Bruns-Garland syndrome of diabetic amyotrophy. Trans Am Neurol Assoc 1977;102:1-4.
27. Asbury AK. Focal and multifocal neuropathies of diabetes. In Dyck PJ et al. (Eds). Diabetic neuropathy". Philadelphia: Saunders 1987:43-55.

28. Said G, Goulon-Goeau C, Lacroix C, Moulonguet A. Nerve biopsy findings in different patterns of proximal diabetic neuropathy. Ann Neurol 1994;35:559-569.

29. Coppack SW, Watkins PJ. The natural history of diabetic femoral neuropathy. Q J Med 1991;79:307-313.

30. Dyck PJ, Norell JE, Dyck PJ. Microvasculitis and ischemia in diabetic lumbosacral radiculoplexus neuropathy. Neurology 1999;10:2113-2121.

31. Llewelyn JG, Thomas PK, King RHM. Epineurial microvasculitis in proximal diabetic neuropathy. J Neurol 1998;245:159-165.

32. Said G, Lacroix C, Lozeron P, Ropert A, Planté V. Inflammatory vasculopathy in multifocal diabetic neuropathy. Brain 2003; 126:376-385.

33. Krendel DA, Costigan DA, Hopkins LC. Successful treatment of neuropathies in patients with diabetes mellitus. Arch Neurol 1995;52:1053-1061.

34. Duchen LW, Anjorin A, Watkins PJ, Mackay JD. Pathology of autonomic neuropathy in diabetes mellitus. Ann Int Med 1980; 92:301-303.

35. Hotamisligil GS. Inflammation and metabolic disorders. Nature 2006;444: 860-867.

36. Mitra AK, Del Core MG, Agrawal DK. Cells, cytokines and cellular immunity in the pathogenesis of fibroproliferative vasculopathies. Can J Physiol Pharmacol 2005;83:701-715.

37. Said G, Elgrably F, Lacroix C, et al. Painful Proximal diabetic neuropathy: Inflammatory nerve lesions and spontaneous favourable outcome. Ann Neurol 1997;41:762-770. 